\title{
LA MUERTE PREMATURA DE MUJERES EN LOS ALTOS DE CHIAPAS. UN ANÁLISIS DESDE LA VIOLENCIA
}

\author{
Graciela Freyermuth Enciso \\ gracielafreyermuth54@gmail.com \\ CIESAS-Sureste \\ Hilda E. Argüello Avendaño \\ hildaeu@gmail.com \\ URV/CIESAS-Sureste \\ México
}

\section{RESUMEN}

Este artículo describe y analiza las formas en que los distintos niveles de violencia se concatenan durante la vida, como en la forma de morir, de mujeres en edad reproductiva de Los Altos de Chiapas. La discusión se centra en el análisis de las relaciones sociales en el ámbito institucional, entre las personas, y entre las instituciones y las personas. El análisis se realiza a través de historias individuales y muestra la sociedad en la que viven y fallecen estas mujeres. Pobreza, rezago, insensibilidad, naturalización, encubrimiento, omisión o comisión de la violencia, resultan en efectos perniciosos directos en la salud, educación, y en la posibilidad de sobrevivencia.

Palabras clave: violencia y salud, violencia estructural, muerte prematura, mortalidad femenina. 


\section{ABSTRACT}

This article describes and analyzes the ways in which different levels of violence are linked together during the lives of women of reproductive age in the Los Altos region of Chiapas and the ways in which they die. Discussion is focused on an analysis of social relationships at the institutional level, between individuals, and between institutions and individuals. The authors conduct their analysis through individual histories, and demonstrate the society in which these women live and die. Poverty, backwardness, insensitivity, naturalization, concealment, omission and commission of violence all result in direct harmful effects on the health and education of these women and their possibilities for survival.

Key words: violence and health, structural violence, premature death, female mortality. 


\section{VIOLENCIA Y SALUD, MUERTE PREMATURA DE MUJERES}

Este artículo pretende describir y analizar las formas en que los distintos niveles de violencia se concatenan, tanto durante la vida como en la forma de morir, de mujeres en edad reproductiva de Los Altos de Chiapas. ${ }^{1}$ Para ello recurrimos a la experiencia de la Casa de Salud de la Mujer Indígena, ${ }^{2}$ proyecto al que se dio acompañamiento desde su inicio —año 2002 - hasta 2006, y a la información obtenida con la investigación Mortalidad Materna en Regiones Indígenas, ${ }^{3}$ que implicó la identificación de los fallecimientos en las mujeres en edad reproductiva ocurridos en Los Altos de Chiapas durante 2001 -226 casos en 18 Oficialías del Registro Civil de 17 municipios_— ${ }^{4}$. El trabajo de campo y archivo se realizó entre 2003 y 2005, haciendo el seguimiento de los casos a través de entrevistas — elaboradas ex profeso y adaptadas al contexto indígena - a familiares de 190 de las 226 mujeres, con una estrategia ${ }^{5}$ que permitió identificar a aquellas cuya muerte pudo ser provocada por causas maternas aunque no esté así registrada. No obstante de que esta investigación pretendía principalmente la identificación de muertes maternas, documentamos todos los casos de defunción. Algunas de las muertes, incluso no maternas, pueden también ser consideradas prematuras y evitables.

En este documento, la discusión no se enfoca en la violencia física, ${ }^{6}$ en la que se agrede y causa lesiones corporales a otra persona, sino que más bien está dirigida al análisis de las relaciones sociales en el ámbito institucional, entre las personas, y entre las instituciones y las personas. Es ahí adonde apuntamos, a la «violencia estructural» que determina muertes prematuras o la disminución de la calidad de vida de las personas, por decisiones institucionales o personales; condicionadas por lo económico, político o religioso, y por los usos y costumbres de una sociedad, según sea el momento histórico.

Se parte de que la violencia social interviene en las muertes tempranas de mujeres resultantes de la inequidad ${ }^{7}$ de género, caracterizada por la violación reiterada y sistemática de sus derechos humanos, tales como el acceso a la salud, vivienda, alimentación, educación, y a un medio ambiente limpio. A esto denominamos violencia estructural ${ }^{8}$ 
(Jones 2000, Joxe 1981, Galtung 1981), que de acuerdo con las características descritas puede considerarse institucionalizada, pues frente al rezago social los gobiernos no han establecido políticas para remontar tales inequidades. ${ }^{9}$ Dicho rezago determina un acceso limitado a los servicios de salud y de procuración de la justicia, hecho que dificulta la reparación del daño en los casos de violencia o la sobrevivencia en los de enfermedad o accidente.

El segundo nivel de análisis corresponde a la «violencia mediada por las personas», que puede darse de manera cotidiana, conformada culturalmente en la medida en que exista una distribución inequitativa del poder, y manifestarse mediante el control y el dominio de unas personas sobre otras, a las que ocasionan daño o perjuicio físico, psicológico o de otra índole (Corsi y Peyrú 2003). Esta violencia puede ser ejercida intencionalmente o sin intención, mediante actos de comisión o de omisión. Generalmente, las relaciones sociales inequitativas y desiguales entre personas, ya sea por su género, raza o generación, ocurren en espacios institucionales como la familia, la escuela o los centros de salud, por lo cual los perpetradores pueden ser parte de las instituciones del gobierno federal, estatal o municipal, de organizaciones comunitarias, o de la propia familia. Es así que estas relaciones sociales inequitativas y desiguales, en un marco de desregulación e impunidad, hacen posible la perpetuación de la violencia estructural y van configurando marcos de referencia que, aunque pueden ser violentos, moldean a las instituciones ${ }^{10} \mathrm{y}$ éstas a la sociedad.

Corsi y Peyrú identifican operaciones y procesos de minimización y ocultamiento que hacen difícil reconocer la violencia social, sus causas y sus agentes; tales procesos operan en cada individuo y mediante los sistemas de comunicación, sean públicos o privados, afectando a amplios sectores de la población. Los procesos básicos de desconocimiento que Corsi y Peyrú identifican son: invisibilización, naturalización, insensibilización, y el encubrimiento de la violencia. Sin embargo, estos procesos básicos de desconocimiento se potencian con operaciones facilitadoras de la violencia; en el caso que nos ocupa operan minimizando la importancia de los costos materiales y humanos que la violencia genera 
- y que puede llevar a la muerte—; negando y desconociendo no solo los costos o el significado de los actos violentos, sino también su misma existencia; subrayando las características de las diferencias en los distintos grupos humanos, exaltando e idealizando los logros pero excluyendo o minimizando los obstáculos o los fracasos.

Un tercer elemento que hace posible la perpetuación de la violencia es la «internalización», por parte de las personas afectadas o de las víctimas, de su condición de subordinación que les confiere una limitada capacidad para tomar decisiones en diversos ámbitos como la familia, la comunidad o las instituciones gubernamentales, o para exigir el cumplimiento de sus derechos permitiendo igualmente la perpetuación de la violencia estructural. Como señalamos, la pertenencia a un grupo étnico, a un género y a una generación en particular, son los elementos que de manera individual o en conjunto conforman relaciones estructuradas o posiciones del sujeto que operan como punto de referencia, y que lo colocan en una situación particular de vulnerabilidad/fortaleza, confiriéndole una manera especial de enfrentar los actos violentos, siendo muchas veces tolerados, aceptados, justificados y minimizados por las propias víctimas.

Bajo esta perspectiva, nos interesa analizar cuatro casos de mujeres que vivieron situaciones violentas, y dos casos paradigmáticos de muertes de mujeres en edad reproductiva ocurridas por causas prevenibles; el conjunto nos permite ilustrar los tres niveles de violencia ya señalados.

\section{ESTADÍSTICA DE LA MUERTE}

La violencia estructural hacia las mujeres indígenas de la región Altos de Chiapas se puede reconocer en su acceso limitado a vivienda digna, a un ingreso que les permita una alimentación suficiente, o a un sistema educativo a partir del cual adquirir capacidades para demandar sus derechos básicos. La estimación de pobreza realizada por el Consejo Nacional de Evaluación de la Política de Desarrollo Social, Coneval, ${ }^{11}$ para el año 2008 reveló que: $76.7 \%$ de la población de Chiapas vivía en condiciones de pobreza 
multidimensional, y que $35.4 \%$ de ésta podía ser considerado en pobreza extrema. El mismo informe puso de manifiesto que $75.8 \%$ de la población indígena del país vivía en la pobreza y $39.2 \%$ en la pobreza extrema, cifra $29 \%$ mayor a la de la pobreza extrema a escala nacional. También se demostró que la población de Chiapas presentaba rezagos importantes en seguridad social -70 a $90 \%$ - y en el acceso a los servicios de salud -40 a $60 \%$.

Esto se materializa en el hecho de que las mujeres indígenas de Los Altos tienen una menor posibilidad de sobrevivencia que sus pares femeninos que habitan en otros municipios no indígenas de la entidad, lo que podemos ilustrar a partir de las tasas diferenciales de mortalidad en edad reproductiva por regiones. Las tasas de mortalidad de mujeres en edad reproductiva de los municipios con más de 70\% de hablantes de lengua indígena, HLI, se han mantenido a una distancia considerable de las encontradas en municipios con menos de $70 \%$. A mayores proporciones de población indígena en los municipios corresponden tasas de mortalidad femenina más elevadas (cfr. Gráfica $1^{*}$ ).

\section{Gráfica 1}

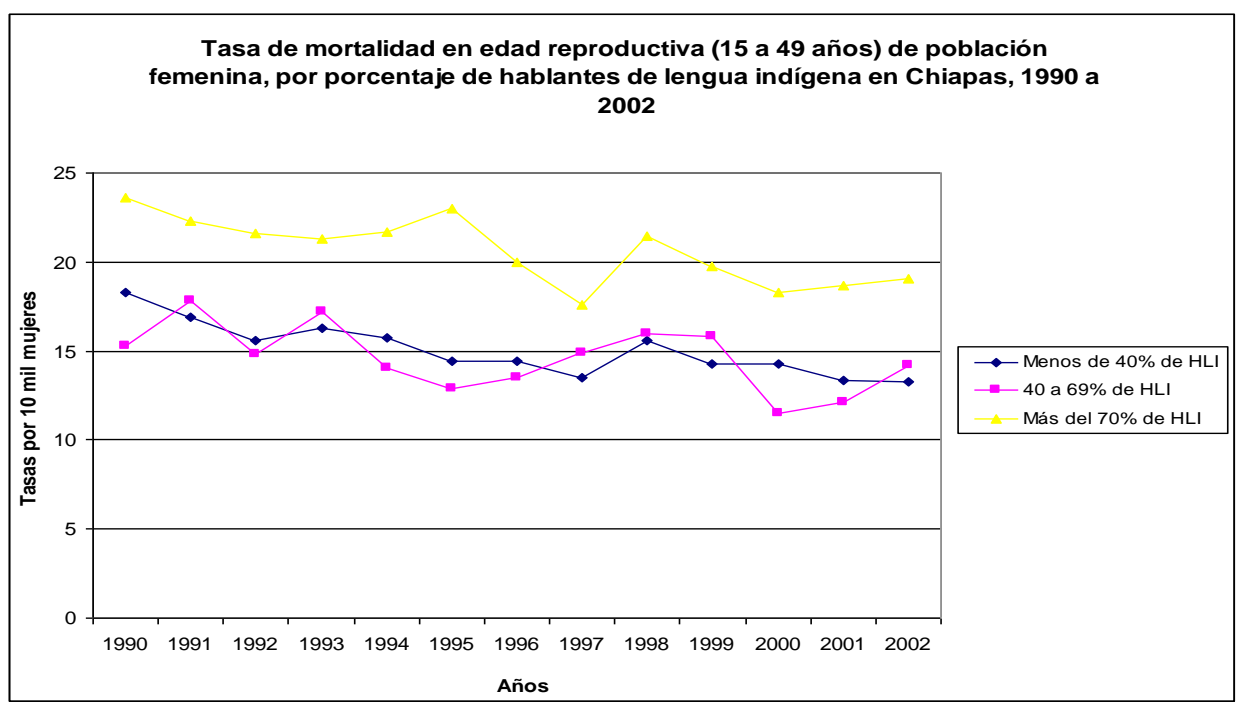

Fuente: Freyermuth, Graciela y Cecilia de la Torre, a partir de las bases de datos de Estadísticas Vitales del Inegi y proyecciones de la población, basadas en el Censo General de Población y Vivienda 1990 y 2000, y en las tasas de crecimiento publicadas en la Agenda Estadística 2000.

\footnotetext{
* ver anexo pág. 208, cuadro 1.
} 
La muerte femenina en edad reproductiva revela también diferencias significativas entre los municipios según la proporción de mujeres analfabetas, resultando directamente proporcionales (cfr. Gráfica $2^{* *}$ ).

Gráfica 2

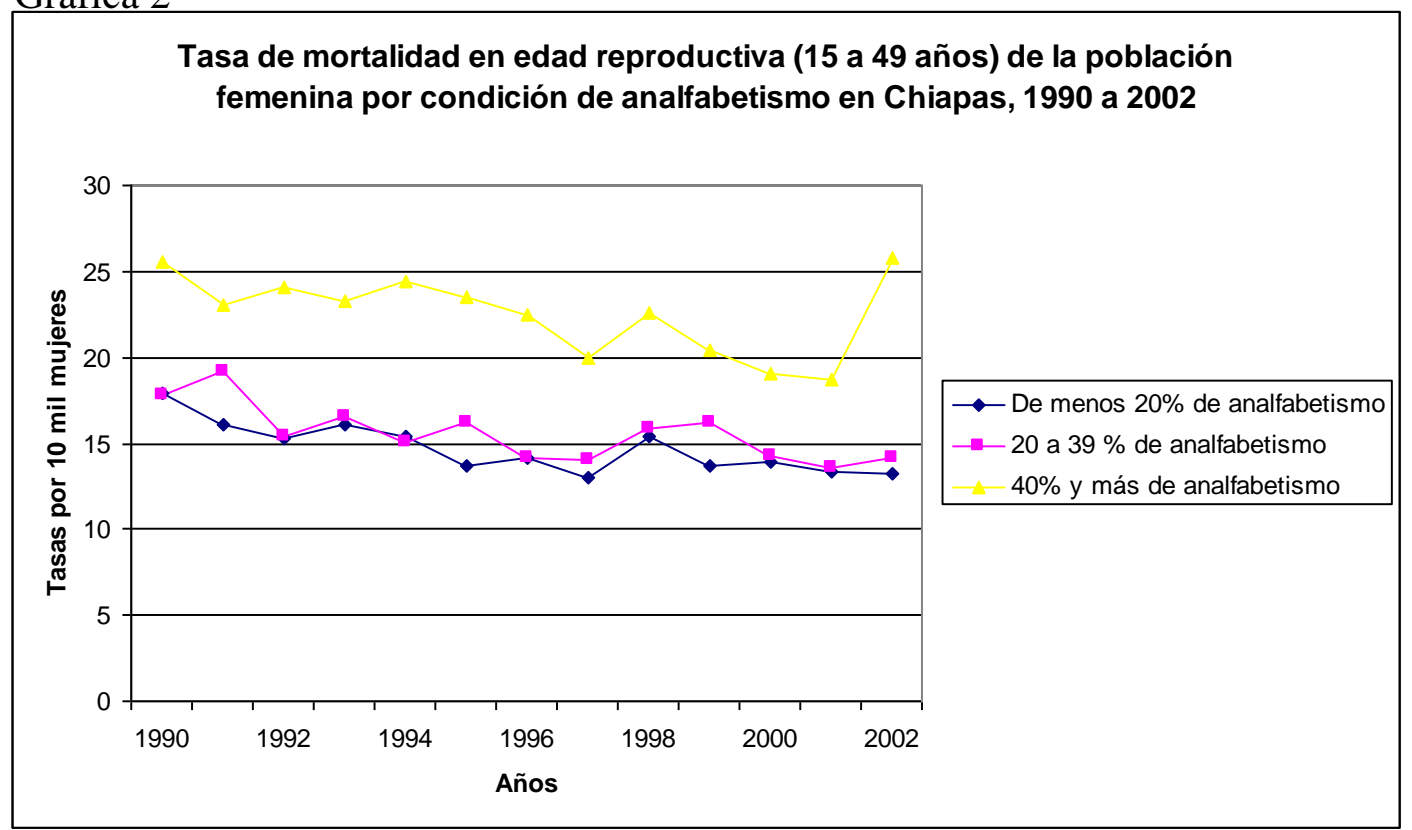

Fuente: Freyermuth, Graciela y Cecilia de la Torre, a partir de las bases de datos de Estadísticas Vitales del Inegi y proyecciones de la población, basadas en el Censo General de Población y Vivienda 1990 y 2000 , y en las tasas de crecimiento publicadas en la Agenda Estadística 2000.

Las diferencias en las tasas no son tan evidentes según regiones, aunque se incrementan en las de Altos y Sierra si las comparamos por quinquenios. Si el análisis se realiza por año, estas diferencias se aprecian disminuidas (cfr. Freyermuth 2008). Los diferentes comportamientos de la mortalidad femenina según analfabetismo municipal, proporción de HLI, e inclusive según región, no siguen el mismo patrón que la mortalidad masculina, cuyas tasas con respecto a HLI o al porcentaje de analfabetismo muestran una trayectoria errática y no presentan diferencias consistentes, como se puede apreciar en Gráfica $3^{* * *}$.

\footnotetext{
** $\quad$ ver anexo pág. 208, cuadro 2.

*** ver anexo pág. 208, cuadro 3.
} 
Esto parece responder al uso diferencial que hacen hombres y mujeres de los servicios de salud, pero sobre todo a la causalidad de la muerte masculina.

\section{Gráfica 3}



Fuente: Freyermuth, Graciela y Cecilia de la Torre, a partir de las bases de datos de Estadísticas Vitales del Inegi y proyecciones de la población, basadas en el Censo General de Población y Vivienda 1990 y 2000, y en las tasas de crecimiento publicadas en la Agenda Estadística 2000.

Las muertes ${ }^{12}$ por enfermedades infecciosas y parasitarias, enfermedades del sistema respiratorio, enfermedades del sistema digestivo; y, en el caso de las mujeres, la muerte materna, sugieren la existencia de inequidades económicas y genéricas —violencia estructural-, ya que $41 \%$ de los fallecimientos de mujeres ocurren por estas causas, contra $34 \%$ entre los hombres. Mientras la tercera parte de los hombres muere por causas externas de morbilidad y mortalidad, $33 \%,{ }^{13}$ menos de la décima parte, $9 \%$, de las mujeres fenecen por estas razones, resultando así que un porcentaje más elevado de mujeres pierde la vida por enfermedades prevenibles. Por ello, el dominio de la lengua oficial y el acceso a la información se vuelven indispensables para la sobrevivencia femenina más que para la masculina, a la luz de que los hombres de cualquier clase social u origen étnico son menos 
proclives a buscar atención médica ${ }^{14}$. Se hace patente que la alfabetización de las mujeres y su conocimiento del idioma español son altamente influyentes en la salud de la familia en su conjunto. Para estas inequidades, que responden más a la violencia estructural, no es posible identificar un perpetrador en particular pues son las instituciones que tienen a su cargo la educación, la salud y la equidad de género, las que tendrían que promover programas específicos que atenuaran estas desigualdades. También son las que deberían visibilizar estas problemáticas y otorgarles su justa dimensión, evitando exaltar de manera desproporcionada los logros gubernamentales, asumiendo las desigualdades e inequidades existentes entre las ciudadanas mexicanas.

\section{CONFLICTOS LOCALES. USOS Y COSTUMBRES}

Un segundo nivel de reproducción de la violencia está mediado por las personas. En él intervienen mujeres $\mathrm{u}$ hombres perpetradores de manera directa o insertados en las instituciones, generando una respuesta social e históricamente modelada; respuesta que puede estar encaminada a sancionar estos actos, a mostrarse negligente ante ellos, hacer omisión de los mismos o, en el extremo, realizar actos de comisión que ocultan estas prácticas violentas y las minimizan impidiendo su visibilización, la identificación de sus causas y sus agentes, así como la impartición de la justicia.

A continuación incluimos algunos casos que consideramos paradigmáticos en la reproducción de este tipo de violencia y en cuya reproducción participan autoridades estatales, municipales y locales.

\section{Caso 1}

El miércoles 30 de junio de 2001 fue asaltada una de las parteras pertenecientes a una organización de Los Altos de Chiapas. Se dirigía a su localidad después de haber acudido a una festividad en la cabecera municipal. Ella era la encargada del resguardo de las ofrendas recogidas en un acto religioso; otras parteras le habían sugerido que no fuera a su casa porque podría ser asaltada, pues muchas personas 
sabían que portaba el dinero de las ofrendas. Durante el asalto opuso resistencia y fue golpeada brutalmente, siendo trasladada inconciente por sus hijos a San Cristóbal de Las Casas. Durante su estancia en el hospital nadie dio parte al Ministerio Público, por lo que la líder de la organización de parteras sugirió que debía realizarse una denuncia, dirigiéndose para ello a la Secretaría de Pueblos Indios, Sepi, donde se entrevistó con la abogada luego de una larga espera. Los hijos de la víctima, al saber que se había acudido a denunciar el caso, pidieron el alta voluntaria del hospital. La líder solicitó a la abogada que la acompañara a la cabecera municipal para dar seguimiento al caso, pero ésta se negó, argumentando que solamente proporcionaban apoyo cuando una persona estaba ya dentro de un proceso legal, y que intervendría sólo en caso de que la agraviada directa quisiera denunciar.

Este es un caso del fuero común en el cual una persona es atacada y golpeada para robarla. Hay elementos que llaman la atención. Por un lado, las prácticas de omisión de los servicios de salud, ya que están obligados a solicitar la actuación del Ministerio Público, MP, en los casos de lesiones ocasionadas por actos violentos o accidentes; en éste, las condiciones de ingreso de la mujer, severamente golpeada, ameritaban la intervención inmediata de MP. Por otra parte, la actitud de la abogada de Sepi, que considera que no hay delito a menos que la propia interesada solicite su apoyo, ni siquiera se cuestionó si los propios hijos estarían involucrados en el asalto, dada la premura para externarla del hospital al conocer la denuncia. En realidad, la actitud de los hijos respondía a una total desconfianza en las autoridades mestizas, ellos prefirieron privar a la madre de la atención hospitalaria ante la perspectiva de involucrarse en un proceso legal.

\section{Caso 2}

Una partera que decía tener 40 años -aunque aparentaba menos-, era frecuentemente golpeada por su marido debido a que no podía tener hijos — hecho comprensible, puesto que había sido sometida a salpingoclasia ${ }^{15}$ en los servicios de 
salud, con la propia autorización del esposo- Era obligada por el marido a procurar a otra mujer en su casa como segunda esposa. La primera mujer que fue llevada no pudo embarazarse, por lo que después de dos meses el hombre la corrió de la casa. Una segunda mujer — también convencida por la partera- es con la que el esposo vive actualmente.

La partera entró en contacto con la organización, en donde conoció del derecho a vivir sin ser maltratada. Un día en que el marido llegó incluso a dispararle con un rifle huyó de la casa, dirigiéndose a la cabecera municipal en busca del juez de paz. $\mathrm{Al}$ conocer la noticia los mayoles acudieron a la vivienda del esposo, siendo citado al día siguiente para resolver el conflicto. El esposo argumentó que golpeaba a su esposa debido a que no podía tener hijos, por lo que el juez le dio la razón, mientras que la mujer señaló que estaba dispuesta a separarse siempre y cuando se le concediera una fracción del cafetal, parte de su patrimonio. El juez sentenció que el esposo tenía la razón y que ella no debía separarse, afirmando que se le llamaría la atención para que no la maltratara pero que estaba obligada a permanecer en la misma casa. Se firmó un acuerdo y al poco tiempo la mujer fue golpeada nuevamente, por lo que decidió trasladarse a San Cristóbal de Las Casas. Actualmente labora en una vivienda como empleada doméstica y sus hijos estudian en Zinacantán y San Cristóbal.

Las autoridades y el juez de paz de las comunidades resuelven los conflictos favoreciendo a los hombres, es por ello que las mujeres manifiestan que «el denunciar es una acción vana», pues siempre se les señalará como culpables y no obtendrán beneficio alguno.

De acuerdo con los usos y costumbres, los maridos pueden aplicar medidas «correctivas» a las mujeres cuando éstas «tienen delito». Tales «delitos» van desde el incumplimiento en las labores del hogar y los accidentes sufridos por los hijos -atribuidos siempre al descuido de la madre-, hasta el adulterio y la incapacidad para concebir. Este último 
justifica el ingreso a la casa de una segunda esposa. Aunque en la región son cada vez menos los hombres que tienen dos o más mujeres, aún es una práctica vigente, reservándose el «privilegio» para aquellos con cierto prestigio social o capacidad económica. Como se dijo, la esterilidad de la pareja es el argumento que más se esgrime para justificar la cohabitación con más de una mujer en el hogar. Debido a que es deseable que el ingreso de una segunda mujer — generalmente mucho más joven — se dé con la anuencia de la esposa; en este caso ocurrió que la primera «buscara» a la segunda. Esto puede asegurar cierta armonía doméstica, adoptando la primera más el papel de suegra, vigilando el comportamiento de la más joven e instruyéndola en los quehaceres de la casa. Es importante destacar, en este caso, el hecho de que el pretexto para adquirir una segunda mujer fuera la esterilidad secundaria de la primera esposa, jsecundaria a una oclusión tubárica quirúrgica y evidentemente autorizada por el marido! En la lógica del juez de paz esto no privaba al marido del derecho a una segunda esposa y de excluir a la primera. Este caso ilustra la contradicción entre las políticas públicas — programas de planificación familiar - y los usos y costumbres — sentencias del juez de paz-, demostrando que son las mujeres quienes llevan la peor parte en la medida en que los sistemas de procuración de justicia no velen por sus intereses.

\section{Caso 3}

El 9 de septiembre de 2005, una señora fue golpeada y obligada a salir de su casa por el hombre con el que vivía y su primera esposa, despojándola de su hijo y del dinero que había recibido del Programa Oportunidades. ${ }^{16}$ Inmediatamente el hombre maltratador se dirigió a la casa de sus suegros y les dijo que había corrido a la mujer porque no obedecía y porque le había encontrado una carta de otro hombre. Esto ocasionó que cuando la joven solicitó ayuda de sus padres, la arrastraran por la calle, la golpearan y no la dejaran entrar en la casa. Ante esta situación, un grupo de parteras organizadas le dieron albergue. Una partera fue a hablar directamente con los padres y a interceder ante la familia para que le permitieran vivir en su casa, ya que la joven no tenía adónde ir. La madre contestó que «ella era una perra y que 
tenía razón el marido al haberla corrido». La joven, llorosa, fue a refugiarse con una familia vecina. Las parteras no quisieron ir a denunciar el caso con el juez porque el padre de la joven es el agente municipal y porque el juez ha dicho que cuando una esposa o hija de una autoridad tiene un problema nadie puede intervenir, porque entre ellos tienen la capacidad de resolverlo.

\section{Caso 4}

También en el año 2005, una joven estudiante de secundaria de 15 años se vio seducida por el hijo de su padrastro, que siendo casado le decía: «¡cásate conmigo! Yo no tengo mujer; yo a mi mujer la voy a regresar con su papá». Tuvieron relaciones sexuales, resultó embarazada por lo que fue objeto de burla del joven. Temiendo la ira de su madre no le informó del embarazo. Cuando inició el trabajo de parto la madre de la joven acudió con las parteras para que la atendieran de «un dolor de estómago», al enterarse que estaba a punto de dar a luz estalló en improperios, desentendiéndose de ella: «ahí la miran a mi hija, si se alivia acá o no se alivia acá, si se va a San Cristóbal, a mí no me importa; yo de por sí no sabía que estaba embarazada, ¡maldita! Pero yo no tengo dinero, no tengo cómo pagar carro, ahí lo ven de dónde sacan dinero». Luego, echándola de la casa, va a denunciarla a las autoridades acusándola de involucrarse con un hombre casado. A unas horas del nacimiento, las autoridades municipales irrumpieron en la casa de las parteras con la intención de arrestar a la joven. La intervención de una asesora mestiza de las parteras les hizo ver que el único delito existente lo había cometido el hombre casado al tener relaciones con una menor de edad, decidiendo entonces arrestar al joven hermanastro. Este conflicto ocasionó la furia del padrastro hacia la joven y su exclusión definitiva del hogar, por lo que debió irse a vivir con su hermana mayor, madre de dos hijos pequeños y empleada en un establecimiento dedicado a la venta de bebidas alcohólicas. 
Como se indicó en la primera parte de este documento, en la región Altos se localizan los municipios con los mayores índices de rezago social y con los porcentajes más elevados de pobreza alimentaria por municipio. De acuerdo con los usos y costumbres, durante la negociación del matrimonio la familia del hombre debe retribuir a la familia de la mujer, mediante obsequios, dinero o trabajo, los cuidados, educación y adiestramiento para el trabajo doméstico que ha recibido la pretendida durante toda su vida, así como por haber conseguido que esta llegara virgen al matrimonio. Generalmente, las nueras pasarán a formar parte orgánica de la familia del marido y contribuirán con su fuerza de trabajo, ya que la residencia permanente de las parejas será patrilocal. Así, las suegras, más que las madres, resultan las beneficiarias del cuidado de las jóvenes que se unen en matrimonio. Un embarazo fuera del matrimonio no solo representa una pérdida al frustrarse una negociación matrimonial, sino una carga adicional para la familia que deberá alimentar al producto del embarazo.

Los casos 2 y 3 dan luz sobre las relaciones previsiblemente conflictivas en hogares con dos esposas, que con frecuencia se resuelven o atenúan con la expulsión de una. En el caso 3, la joven fue echada por su marido y la primera esposa, pero para que un acto de esta naturaleza quede impune será fundamental llegar a un acuerdo, ya que de otra manera se establecerá un conflicto permanente entre las dos familias con un costo económico para alguna de ellas. En este caso, también es evidente que la familia de origen no está dispuesta a alimentar una boca más, y menos dos, por lo que ni figura discusión alguna acerca del destino del pequeño.

Igualmente, en el caso de la joven estudiante la preocupación principal de la madre es apartarla de su vida, lo que le eximirá de contribuir con los gastos del parto. Ponerse del lado del hijastro, y por lo tanto de su esposo, le representa el menor costo económico. En otro sentido, los antecedentes respecto de la forma de vida de la hermana —en la región, los bares o cantinas frecuentemente son sitios desde los cuales muchas mujeres son introducidas a la prostitución - ${ }^{17}$ coloca a ambas jóvenes y a sus hijos en una situación de 
profunda vulnerabilidad. Destaca la actitud de las autoridades que se desisten de castigar a la joven parturienta gracias a la intervención de una caxlana o mestiza, al clarificar quién había incurrido en delito.

La revisión de estos casos muestra el impacto de la violencia mediada por personas, mismos que ilustran cómo la violencia del cónyuge se ve naturalizada por la intervención de otras personas, ya sean servidores públicos o los integrantes de la propia familia. Esto hace posible su minimización y por tanto su reproducción a través de actos de omisión y comisión.

También nos muestra que las políticas de salud pueden tener implicaciones futuras en la vida de las mujeres; partiendo de concepciones de la vida distintas, en las comunidades indígenas estas políticas no guardan relación con las formas de procuración de justicia. Las normas vigentes a escala nacional sobre los derechos de las mujeres no van paralelas con la impartición de justicia basada en usos y costumbres. Las formas de resolución de conflictos que operan en este tipo de localidades van marcando pautas de comportamiento en la sociedad, y a través de ellas no solamente se va construyendo la impunidad, sino que también se perpetúa la violencia. Estas historias muestran el abismo presente entre las estructuras jurídicas y la penosa existencia de las mujeres indígenas.

\section{LAS HISTORIAS DE MUERTE}

\section{LA MUERTE DE LUCÍA}

Lucía murió cuando tenía 35 años. Su acta de defunción fue certificada por un agente municipal quien asentó como causa de muerte «calentura y gripe». La defunción se clasificó oficialmente como «influenza debida a un virus no especificado». Esta mujer vivía con su cónyuge y sus hijos en una localidad cercana a la ciudad de San Cristóbal de Las Casas, profesaba la religión católica, era analfabeta y no hablaba español, su lengua materna era el tsotsil. Mariano, su padre, dice que su yerno sólo la golpeaba «de vez en 
cuando», y nunca cuando estaba sobrio. Mariano no conoce con precisión la causa del fallecimiento.

Ya no estaba embarazada, ya había nacido su bebé cuando falleció mi hija. La verdad, no sabemos nada más. Nos dijeron que tenía un tumor en su estómago. Nunca nos dijo la partera que mi hija tenía algo en su estómago; hasta cuando ya estaba grave me dijo que tenía algo. Tenía ocho meses cuando nació, el bebé no cumplió los nueve meses. La enfermedad duró como un día después del parto; ya no resistió mi hija al momento que pasó el parto. Se murió. Lo único que le daba era dolor de estómago, es lo único que nos decía... poquito, que le dolía su cabeza, no se quejó mucho. Lo que hicimos fue traer a unos curanderos para venir a ver a mi hija, nos dijeron que estaba muy grave, que era imposible curarla. Nada más decía que le dolía su estómago, pero nunca quiso ir al doctor. Cuando ya estaba grave, la partera nos dijo que tenía una bola en su estómago pero no sabía de qué era.

Los partos previos de Lucía habían sido atendidos por la partera. Tuvo seis hijos, el del último embarazo nació muerto. El seguimiento del embarazo lo hacía la partera, a pesar de que era beneficiaria del Programa Oportunidades y por tanto su control prenatal debía haberse realizado en alguna clínica.

De los otros hijos, nunca tuvo problemas después de nacido el bebé, nunca se quejó de dolor, pero no sé qué habrá pasado ahora, tal vez la partera no le vio a tiempo el tumor que tenía mi hija.

Nunca fue al doctor porque le daba pena, sólo con la partera tenía más confianza. No la sacamos de aquí porque mi hija no quería, por eso no la sacamos, porque ya estaba muy grave. El bebé nació pero estaba muerto, al momento que nació mi hija se murió. No la curó nadie, era demasiado tarde cuando nos enteramos, ya no podíamos salvarla. Ya no la salvaron. El curandero y la partera no pudieron. 
OMISIONES Y COMISIONES, FACETAS DEL PODER INSTITUCIONAL

Es evidente que para los funcionarios implicados en el registro de esta muerte la causa del fallecimiento no era relevante, ni siquiera mereció su correcto registro. La incongruencia entre la causa real de la muerte y la causa registrada sugiere actos de omisión y ocultamiento. A partir del año 2000, con la aparición del programa gubernamental Arranque Parejo en la Vida $^{18}$ en el ámbito federal, y con una política intencionada del gobierno del estado de Chiapas para disminuir la muerte materna, el ocultamiento de estas muertes se volvió frecuente; lo ocurrido con Lucía es muestra de ello. Era beneficiara del Programa Oportunidades, y sólo por ello debió haber sido objeto de control médico durante su embarazo; su muerte revela los límites de los programas de trasferencias económicas si no van aparejados con lineamientos que aseguren que las beneficiarias dispongan de acceso oportuno a los servicios de salud en caso de urgencia obstétrica.

\section{VIOLENCIA MEDIADA POR PERSONAS E INTERIORIZADA POR LA VÍCTIMA}

El caso de Lucía no es un caso extremo de violencia doméstica como los analizados en el apartado previo; podemos reconocer que durante el parto y su muerte se le procuró atención con los recursos locales disponibles para la familia. Sin embargo, la cercanía de la localidad de origen a la ciudad más importante de la región —San Cristóbal de Las Casas—, y el lapso entre el nacimiento y la muerte habrían permitido su traslado a un hospital; siendo beneficiaria de Oportunidades necesariamente había tenido contacto con el personal de los servicios de salud. Las representaciones que la familia tiene sobre la enfermedad durante el parto y las relaciones interétnicas entre indígenas y mestizos son elementos que determinan la aceptación de una, o como en este caso, de dos muertes prematuras. También los laxos vínculos entre los agentes tradicionales de salud - curandero y partera - y los servicios de salud vuelven común la ocurrencia de estas muertes.

\section{LA MUERTE DE MARCELA}

Marcela falleció cuando tenía 30 años y cuatro hijos. Al indagar sobre este caso habían pasado seis años desde que se separó del esposo y regresó a vivir en la cercanía de la casa 
materna. El padre de Marcela murió ocho meses antes que ella. Su madre, Marta, cuenta que Marcela era evangélica, hablaba tsotsil y se dedicaba a cultivar café; y que también era beneficiaria del Programa Oportunidades - antes Progresa.

Ella estaba sólo en su casa. Va a cortar su café ... a limpiar su café. Lo que pasa es que es dejada, la dejó su marido... de ahí se quedaron solos. Por eso se quedó con cuatro hijos, tres niños y una niña. Cuando él [su marido] empezó a buscarse otra mujer empezó a portarse muy mal con mi hija, le empezó a regañar, la golpeaba, le pegaba muy feo. Empezó a tomar, se dedicó a tomar. Cuando llegaba a la casa golpeaba a mi hija, mi hija gritaba cada vez que lo pegaba, ya era puro regaño, ya era puro golpe, pero porque quería buscarse otra mujer, por eso empezó a pegarle. Así fue como la dejó y se fue con otra. Ella se quedó con todos sus hijos.

Cuando Marcela se separó estaba embarazada, y su padre exigió al esposo que se hiciera cargo de la manutención. Éste sólo le envió tortillas un par de ocasiones y ni siquiera conoce a la hija producto del último embarazo.

La cuidé a lo mejor un mes; ya no podía ella hacer nada, salía y se caía. Me acuerdo que una vez por poco se quema, pero se levantó solita, y es que ella también ya se desmayaba; cada vez que quería caminar la teníamos que arrastrar porque como que ya no tenían fuerzas sus piernas. Se debilitaron las piernas, quién sabe qué clase de enfermedad tenía.

Durante las últimas tres semanas de vida, Marcela y Marta tuvieron que hacer frente a penosas situaciones para lidiar con la enfermedad que la llevó a la muerte.

Con lo de las muelas comenzó poco a poco; poco a poco se fue agravando, creo que tardó como tres semanas ... pero no digamos que está fuerte y todo, estaba muy débil y además como no tenia esposo, y yo tampoco, ya estábamos solitas; por eso 
me da mucha lástima cómo estábamos viviendo. Fue a quitarse su muela; lo quitó de este lado, luego de este lado, pero ¡qué va!, ¡nunca dejó de sangrar! Lo fue a quitar su diente aquí con los soldados; entonces, como no paraba de sangrar volvió a ir con ellos a pedir una inyección, una medicina para que parara, y entonces sí dejó de sangrar. Paró [el sangrado] donde le habían quitado la muela pero empezó a salir [sangre] por todos lados; en las encías, ahí empezó a salir, de abajo, de arriba, de todos lados, y así salía, noche y día. Salía bastante su sangre. Así fue como empezó a sangrar, y siguió sangrando de la boca. Poco a poco se fue acabando mi hija, fue poniéndose pálida, sus ojos blancos... poco a poco le fue afectando sus manos, sus pies y todo.

Yo le dije que por qué no buscaba su medicina, que fuera con los doctores, que empezara a ver la forma en cómo tiene que curarse: «y es que así como me ves, pues ya no estoy para salir a buscarte medicina, ya no soy fuerte, porque si me esperas pa' que yo te acompañe va a estar difícil porque yo ya soy grande», así le decía a mi hija.

Mi hija, ella misma [buscó atención] se movió todavía, porque trajo inyecciones, pastillas, pero ya ni así, ya ni las pastillas curaron a mi hija; sí se había quitado el sangrado de la boca, pero después le empezó a salir como bombitas en la mano, con eso le empezó a dar calentura, pero bien fuerte. Ya fue que lo llevé a Pantelhó, la inyectaron para que bajara la calentura, y iqué va!, en donde le inyectaron empezó a sangrar bastante; la inyectaron en la pierna y por gotas salía la sangre. Ya fue que le dije al doctor que estaba sangrando mucho — porque me tuve que ir con ella—, y el doctor le dio un algodón, un pedazo de algodón para que pare la sangre. Y así traía su mano, adentro de la falda para detener el algodón. Así fue como nos tuvimos que regresar con ella. Mi hija fue enfermándose, se habían debilitado sus piernas, ya no tenía fuerzas, se caía. Ella todavía trataba de caminar pero se caía, se caía mucho, de repente caminaba hincada, arrastrándose. La primera vez fuimos con doctores particulares, gastamos mucho porque eran carísimas las medicinas, todo lo que le 
hacían a mi hija, todo era caro. Gastamos mucho dinero así nada más, porque ni siquiera se curó... no se curó.

También fuimos a San Cristóbal. Lo llevamos para que le pusieran sangre, fuimos a particular, no fuimos a un hospital gratis. De verdad ahí fue carísimo, para que le dieran sangre, como tres mil quinientos, y en dos [unidades de sangre] salía carísimo. Donde nos hospedamos, ¡híjole!, nos cobraban bien caro, creo que fuimos pagando como dos mil quinientos. Pero dos litros era muy poco, porque el doctor nos pedía tres litros, pero como estaba muy cara [la sangre] los doctores nos lo dieron, así fue como le pusieron la sangre. Ya de ahí nos regresamos, pero el doctor nos había dicho que nos faltaba medio litro; nos dijo que la próxima vez le tenía que poner otro medio litro, y que si no se le pone, dice que se va volver a poner mala, que va a volver a ser lo mismo.

Yo le decía que buscara su medicina, que luchara todavía para que viva. Porque yo le dije: «ya no estoy fuerte, ya no estoy sana, yo también ya estoy grande, estoy enferma». Yo le decía que si ella llegara a faltar quién iba a cuidar a los niños, quién les va a dar de comer, mantener, lavar la ropa. Le decía que ya no soy joven para mantener a sus hijos, para cuidarlos; y ella sólo me contestaba: «sí, sí», así nada más me contestaba. Hicimos todo lo posible para que se salvara; se fue a recibir los medios litros que faltaban, y así fue que llegamos — me acuerdo muy bien—, que llegamos un día domingo acá a la casa, y para el día lunes otra vez volvió a caer nuevamente. Se puso muy grave, y no parece que le estuvieran haciendo algo porque yo no veía que se recuperaba, la veía igual. Me da mucha lástima, porque sólo nosotras estuvimos luchando, viendo las cosas, me da mucha tristeza recordar que sola fui a San Cristóbal, a Tuxtla, y yo no sabía hablar [español]. Porque gastamos mucho, veinticuatro mil pesos, por eso nos quedamos muy pobres, no tenemos nada ahorita, su esposo fue muy irresponsable, no la respetó, no quiso a mi hija. 
La sangre que le pusieron, pues salió toda, como que quiso reventar sangre por todas partes en su cuerpo, como si se le reventara la sangre, como si ya no circulara su sangre en todo su cuerpo, porque hasta ya se veía rojo la piel, así como queriéndose reventar la sangre para que salga en todo su cuerpo. El hospital regional de San Cristóbal y el de Tuxtla fue al último adonde fuimos, el último intento que hicimos nosotras fue ahí. En el hospital de San Cristóbal con tal de que ella viviera

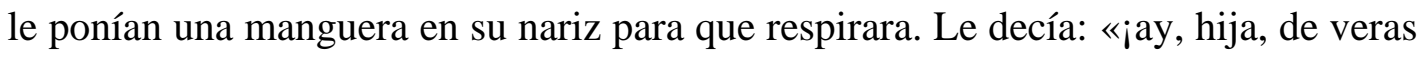
que ya estás muy grave!», pero ella ya no me contestaba. Entonces, cuando me di cuenta que ya no me contestaba, le fui a decir al doctor, y como yo también no sabía hablar, no sabía español, no sabía la castilla, entonces le tuve que decir al doctor con señas, le decía que ya veía muy grave mi hija; así hacía, con señas le hablaba al doctor. Al rato me di cuenta que traían una cama, la cargaron y la pasaron a otra cama, y así la llevaron, ya fue que ellos me dijeron que fuera por mis cosas, porque como llevaba cobijas y todo, entonces que me fuera por ellas, porque a mi hija la iban a llevar a Tuxtla, y pues yo obedecía lo que me decían, yo también sacaba arrastrando mis cosas porque ya no podía, sentía que ya no tenía fuerzas, y así fue que lo llevaron a mi hija en una camilla, la tuvieron que sacar. Nos dijeron que ya no iba a aguantar: «ya no lo va a soportar», dijo el doctor. Cuando llegamos a Tuxtla ella iba con su suero, ahí estaba el suero para que no se pusiera más grave, pero cuando llegamos allá le volvió a subir la temperatura, llegó hasta cuarenta grados, yo le decía: «parece que estás muy caliente, ¿por qué no abres tantito tus ojos», le decía a mi hija, pero ella no me contestaba, ya no hablaba, y pues ellos trataron todavía de ver si se podía hacer algo, pero pues no, ya no, por eso me da mucha tristeza acordarme. Ahí me mandaron a comprar medicinas, y yo les dije a las enfermeras: «yo no sé dónde ir, no conozco, no sé dónde comprar medicinas», les dije a las enfermeras que vivimos muy tristes porque no tenemos a nadie... a nadie. 
Marta conoció en el hospital a un señor llamado Roberto, quien le sirvió como traductor con las enfermeras.

Él no era nada mío, sólo porque él sabía castilla, por eso fue que le pedí de favor que me acompañara. Así fue como nos cruzamos en el camino, nosotras estábamos allá en Tuxtla, y él se venía a San Cristóbal. En Tuxtla todavía le trataron de dar medio litro de sangre y como que sí volvió todavía, y este señor Roberto se regresaba a San Cristóbal y yo no me podía quedar solita, como yo no sabía hablar, no sé hablar, entonces yo no me quería quedar solita ahí con mi hija. Por eso también nos tuvimos que salir del hospital, porque no podía quedarme yo sola, nos tuvimos que venir con el señor Roberto, pensaba que si me quedaba yo sola, no los iba a poder entender, entonces pensé que a lo mejor me lo iban a matar de una vez a mi hija, entonces por eso tuve que venir, y cuando llegamos acá todavía la enfermera lo trató de ver. Sí, así fue como nos regresamos. Como muchos dicen que a veces sí los matan ahí, entonces, yo también tuve miedo, tuvimos que salir. Como yo la veía ya muy grave y ya no podía hablar, decidimos salir del hospital.

El doctor dijo que si queríamos que viviera más tiempo tenía que ponerle cincuenta litros de sangre, y a lo mejor podía vivir como unos seis meses. Pero sabe mejor mi hijo, él sí sabe bien. Mi hijo Miguel nos estuvo apoyando todavía, sí, por eso a lo mejor él sabe mejor que yo.

Miguel cuenta que el doctor les dijo que fue «anemia plástica» ${ }^{19}$

Hasta donde nos dijo el doctor la anemia sí se cura, pero lo que es anemia «plástica» ya no tiene remedio, ya no se cura. Aunque tuvieras mucho dinero, vayas donde vayas, de plano, ya no se puede curar, ya no tiene remedio, por eso fue que tomamos la decisión de sacarla del hospital, porque ya no teníamos dinero, y el doctor nos había dicho que de todas maneras se iba a morir. Ya solo estuvimos 
esperando unos días, porque solo íbamos a gastar sabiendo que ya no se iba a curar. Lo único que nos conformaba es que saliera viva del hospital. Cuando salió del hospital vivió como una semana todavía. Porque cuando salió le pedí un litro de sangre para que estuviera unos días con nosotros. Pero ya cuando se acabó ya no hice nada, porque sabíamos que de todas maneras se tenía que morir.

Marta cree que la enfermedad fue debida a la tristeza, por su preocupación, porque se ponía a pensar cómo iba a conseguir dinero, cómo iba a mantener a sus hijos, cómo iba a comprarles ropa: «como no tiene su esposo a lo mejor por eso pensó mucho».

A lo mejor se ponía a llorar sola, ella sí se ponía a llorar. A mí me lo dijo, que estaba muy triste porque como no tenía esposo se preocupaba mucho, que de dónde iba a encontrar dinero para sus hijos; decía que se sentía muy mal, que es muy triste estar sin... sin el papá de los niños. Desde que nació la niña, ya no volvió a hablar con él. Quisiera que nos tomaran en cuenta, así como se murió mi esposo, estoy solita aquí con los niños, sufrimos mucho porque somos seis en la casa, no hay dinero para comprar maíz, frijoles; no tengo dinero para comprarles ropa, y yo ya no puedo trabajar para mantenerlos. Por eso sufro mucho, y como a mí me operaron ya no puedo trabajar bien. Yo quisiera crecerlos a estos niños, para que después ya no sufran. Sí, que por lo menos éste... verlos crecer. Porque cuando van con otra persona sufren mucho, ya ni les dan de comer, ya no los mantienen. Si se van con la madrastra ya no los cuida bien. ${ }^{20}$

Solamente así como les conté murió, así fue, solamente por eso... sí, solamente por eso; no hay ningún otro problema ... o a lo mejor nos vienen a buscar y nos meten a la cárcel.

\section{DIFERENTES NIVELES DE VIOLENCIA SUCEDEN AL MISMO TIEMPO Y SE CONCATENAN}

Cuando el cónyuge de Marcela quiso una nueva esposa inició el maltrato, sobre todo estando alcoholizado. El hombre se desentendió de los hijos sin llegar siquiera a conocer a 
la más pequeña. Marcela volvió a acercarse a sus padres aunque sin vivir en la casa materna, sino en sus cercanías, trabajando en el cultivo de café para obtener algún ingreso. Como se dijo antes, la situación económica de las familias es un poderoso elemento que configura las relaciones, principalmente con respecto a las hijas. Tal como hemos visto, la violencia del cónyuge se percibe naturalizada; es «normal» que el hombre deje a sus hijos y abandone sus obligaciones, no hay intervención alguna de las instituciones públicas, sólo el padre de la mujer le exige que se responsabilice y la respuesta que obtiene es insuficiente y temporal. No obstante, la internalización de la violencia por parte de Marcela y su familia los conduce a no exigir legalmente sus derechos y a intentar un arreglo informal, no se denuncia el maltrato ni se exige la manutención de los hijos. Es un caso que nos permite ilustrar claramente los componentes mencionados de invisibilización, naturalización, insensibilización, y el encubrimiento de la violencia. La propia Marcela se ve afectada por la internalización de su vulnerabilidad que retroalimenta la perpetración de la violencia mediada por personas a través de actos de omisión y comisión, tanto por parte del cónyuge como de las instituciones públicas o la estructura jurídica vigente en su operación local; y de omisión por parte de ella y sus familiares. Los diversos niveles de violencia se concatenan, se retroalimentan, y de acuerdo con los contextos o con la complejidad de las situaciones podemos ver más acentuadamente uno u otro.

\section{DEL DOLOR DE MUELAS A LA ANEMIA APLÁSTICA}

A pesar de que Marcela era beneficiaria del Programa Oportunidades y por tanto acudía a la clínica regularmente, cuando inició el padecimiento con dolor dental debió asistir a un campamento militar donde se dispone de servicio dental y la atención médica suele ser gratuita para la población de zonas rurales —no así en los medios urbanos-. Es a partir de un sangrado pertinaz, secundario a la extracción de un molar, que se desencadena la búsqueda de atención fuera de la localidad de residencia. La madre alentó a Marcela para buscar atención; tras su muerte, ella se ha hecho cargo del cuidado de los niños, lo cual considera es una tarea muy penosa para ella por su edad y soledad por su reciente viudez. Ambas mujeres buscaron ayuda en otro municipio y en una localidad más grande, Pantelhó, 
sin embargo, no dirigieron sus esfuerzos de inicio hacia un núcleo urbano que les ofreciera una mayor disponibilidad de recursos para la atención médica que pudieran requerir, como es la ciudad de San Cristóbal de Las Casas.

Las dos mujeres iniciaron una espiral de búsqueda de atención infructuosa para remediar la enfermedad de Marcela, quien cada día iba deteriorándose más al igual que sus recursos económicos. Apremiadas por la gravedad de Marcela y la falta de recursos económicos llegaron hasta el hospital general de San Cristóbal de Las Casas, para luego ser enviadas al de Tuxtla Gutiérrez, donde se hicieron más evidentes los obstáculos dictados por el analfabetismo y el monolingüismo, manifestándose en la desesperación de Marta tratando de comunicarse y entender lo que le sucedía a su hija. La invisibilidad de la población indígena ante las instituciones - es obvio que el hospital de Tuxtla Gutiérrez no disponía de traductores de lenguas indígenas - naturaliza a su vez el bagaje de ciertas habilidades que la población debe poseer para hacer uso de los servicios. La percepción de la madre de Marcela respecto de la enfermedad queda relegada a un segundo plano ante el escenario abrumador y demandante que los nuevos contextos le exigían; si fue una afección de las muelas o una anemia aplástica, el diagnóstico es un detalle que poco se recuerda. ${ }^{21}$ Deberá ser la población indígena, y no las instituciones, la obligada a remontar los obstáculos implantados por la lengua, así como la que — sin ayuda — deberá descifrar los códigos y el manejo institucional que se les impone. La insuficiencia de la respuesta institucional pone en manos de la propia población su sobrevivencia. Marta recibe la noticia de que su hija no tiene curación y que si desea que viva un poco más se le deberá suministrar más sangre, lo cual dependerá de sus posibilidades económicas y de sus redes sociales. Ante la inminencia del fallecimiento de Marcela y de la partida de quien la ayudó a comunicarse, se conforma con sacarla con vida del hospital. Esta decisión, que pareciera tomada por la familia, en este caso por la madre de Marcela, en realidad es resultado de un contexto institucional adverso para la población más pobre y rezagada. 
Las dos historias de arriba ilustran crudamente el porqué las mujeres analfabetas y hablantes de lengua indígena tienen tasas de mortalidad más elevadas. No obstante que ambos relatos plantean escenarios diversos - una emergencia sin atención médica oportuna y un peregrinar que demora más de un mes-, culminan con el mismo desenlace fatal y la misma sensación de impotencia. La frecuencia con la que los casos de enfermedad y urgencia terminan en muerte ha llevado a la población indígena a construir un imaginario de fatalidad sobre el acceso a los servicios de salud y la relación con los mestizos; esto desalienta a las familias para la búsqueda de atención en los establecimientos de salud.

\section{CONCLUSIONES}

Las altas tasas de mortalidad femenina en Los Altos de Chiapas, con el consecuente acercamiento entre la mortalidad masculina y la femenina en edad reproductiva, revelan la omnipresencia de una violencia estructural. En la región Altos se encuentran los municipios con los mayores índices de rezago social y con los porcentajes más elevados de pobreza alimentaria por municipio en el país (Coneval 2009). La economía familiar es un elemento de peso que observamos en la configuración de las relaciones de parentesco, principalmente con respecto a las hijas. Los datos que aquí se presentan prueban que la mortalidad femenina es relativamente mayor en municipios con más altos porcentajes de mujeres indígenas y analfabetas, y que los rezagos sociales tienen un efecto más pernicioso sobre las mujeres que sobre los hombres. El dominio de la lengua oficial y el acceso a la información se vuelven indispensables para la sobrevivencia, y el porqué es reconocido a través de las historias presentadas.

Las narraciones documentan de igual manera la forma en que las políticas sociales y de salud pueden contraponerse a los usos y costumbres, y por tanto situar en mayor vulnerabilidad a las mujeres. Particularmente, los programas de planificación familiar con la aplicación de métodos definitivos sin una decisión informada y libre por parte de las mujeres, les crean el riesgo de perder su posición familiar y comunitaria. Prevalecen desventajas entre los sexos por las formas en que se resuelven los conflictos familiares en 
las comunidades indígenas, pasando a ser letra muerta lo establecido en las leyes y normas que pretenden conseguir la igualdad de género o promover una vida sin violencia para las mujeres. La Encuesta de Salud y Derechos de las Mujeres Indígenas, Ensademi, 2008, mostró que de las ocho regiones de estudio en el país, la de Los Altos de Chiapas presentaba la mayor prevalencia de violencia de pareja en los últimos 12 meses - con $41.4 \%$ - y concentró la proporción más alta de violencia severa. Asimismo, la región de Los Altos fue la que en promedio tuvo mayores gastos para la atención de las lesiones producto de la violencia de pareja $-\$ 594$ pesos.

La violencia estructural, ya sea institucionalizada o la mediada por las personas, poco a poco se va naturalizando por parte de los servidores públicos, ${ }^{22}$ los integrantes de la propia familia y por la propia persona. Esto hace posible invisibilizar, minimizar u omitir las situaciones en las que se crea y reproduce la violencia. Todo ello, evidentemente, vulnera la salud y la sobrevivencia de las mujeres y muestra, por tanto, el abismo entre las estructuras jurídicas y su penosa existencia. La omisión ante los casos de violencia, o el evitar las indagaciones - legales o epidemiológicas-, contribuyen a crear un imaginario social dominado por la impunidad. La omisión institucional puede enmascarar las verdaderas causas de la muerte, llegando incluso a imposibilitar la atención oportuna de las propias beneficiarias de los programas gubernamentales. La impunidad ante las faltas administrativas, tanto en el sector salud como en el de la procuración de justicia, es un hecho que hace posible la perpetuidad de la violencia institucional.

No puede soslayarse la responsabilidad de las propias familias —consanguíneas o políticas-, pues en su seno se van construyendo la violencia, la marginación y las muertes prematuras. Las mujeres mayores o en edad madura, llámense suegras o madres, juegan un papel fundamental en la protección y la sobrevivencia de las más jóvenes, pues de su empoderamiento y sensibilidad dependerá la negociación con los hombres del grupo parental para evitar la violencia o las muertes innecesarias. Sin embargo, la capacidad de negociación no es el único elemento presente; la extrema pobreza conduce a la negligencia 
que irrumpe en la realidad, pues en el seno familiar pueden no existir los recursos materiales o la voluntad de movilizarse y buscar la atención que se requiere. La internalización de la violencia conduce a no exigir los derechos ciudadanos. Los diferentes niveles de violencia se concatenan, se retroalimentan, y de acuerdo con los contextos o la complejidad de las situaciones podemos ver más acentuadamente uno u otro; todo ello en un marco de relaciones de desconfianza e incomunicación entre indígenas y mestizos.

\begin{tabular}{|c|c|c|c|c|c|c|c|c|c|c|c|c|c|}
\hline \multicolumn{14}{|l|}{ ANEXO } \\
\hline \multicolumn{14}{|c|}{ 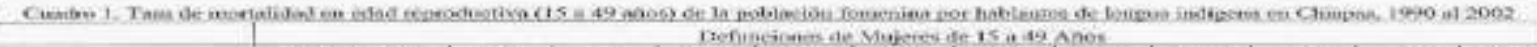 } \\
\hline & 1000 & 1993 & 1902 & 1900s & 1004 & 1905 & 1996 & 1009 & 1998 & 1900 & 2000 & 2001 & ze0a \\
\hline \multicolumn{14}{|l|}{ 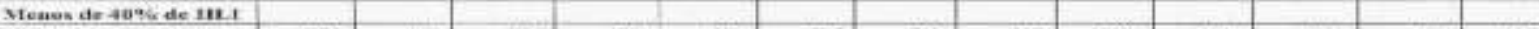 } \\
\hline  & 1007 & 953 & 1009 & 961 & 247 & 0.49 & 605 & $92 n$ & $2 \operatorname{lnk} 2$ & 1014 & 1053 & 9853 & 0205 \\
\hline Namuro de nugieses. & ssso, $98 ?$ & 583.222 & $575,8 \times 7$ & 588,900 & 600.575 & 658.461 & 670.301 & 682.857 & 005.538 & 708.5\$3 & 121,012 & kas.2se & $74 \times, 1$ \\
\hline Tanit de areartalieluted & 18 & 17 & 10 & 16 & 16 & 14 & 14 & 13 & 16 & 14 & it & 13 & 13 \\
\hline \multicolumn{14}{|l|}{ to n work de Hill } \\
\hline  & ky & 100 & es & $10 i 7$ & na) & $\mathrm{kz}$ & $\mathrm{kK}$ & 100 & 100 & 112 & 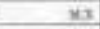 & 90 & ins \\
\hline Nomernen de maierven & 98,102 & 99,428 & 50.737 & 020021 & 01,402 & $6 x^{3}+46$ & $B S 270$ & 07,045 & Gll, 873 & $x 0,700$ & 72,307 & 74,239 & 76,229 \\
\hline 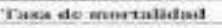 & is & in & is & 17 & 14 & 13 & Ba & is & 16 & 16 & 11 & 12 & 14 \\
\hline \multicolumn{14}{|l|}{ Man dit zons ate thit } \\
\hline Vnimero du nullectian & 191 & 337 & $3 * 3$ & 734 & 340 & 331 & 204 & Ins & 318 & 311 & 208 & $\operatorname{sines}$ & 223 \\
\hline Nàrnctit de revevers. & $14 \mathrm{~B}, 6 \mathrm{2} 2$ & 151.250 & 153.444 & 15.219 & 159570 & 143,26 & 142128 & 150.520 & $1 \leq 4,033$ & 128.000 & 16).323 & 165.062 & $\frac{161) \times 2}{4}$ \\
\hline resca the morralldad & 24 & 22 & 22 & 22 & 22 & $2 x$ & 20 & 18 & 23 & 20 & 1" & 10 & 10 \\
\hline
\end{tabular}

\begin{tabular}{|c|c|c|c|c|c|c|c|c|c|c|c|c|c|}
\hline \multirow[b]{2}{*}{ De menos $20 \%$ de analfinhetixmo } & \multicolumn{13}{|c|}{ Defuncinnes de mujoces de is a th A fion. } \\
\hline & 1990 & 1991 & 1992 & 1993 & 1994 & 1995 & 1996 & 1997 & 1998 & 1999 & 2000 & 2001 & 2002 \\
\hline Niemero de Pallecidan & 755 & 691 & 675 & 727 & 714 & 606 & 729 & 686 & 828 & 746 & $\pi 7$ & 754 & 765 \\
\hline Numers de mujers & 420,880 & 430.605 & 440,686 & 451,139 & 461.986 & 508,394 & 517.4672 & 524.772 & 536,314 & 546,100 & 556,136 & 566.172 & 576,458 \\
\hline Tasa de mortnlidad & 18 & 16 & 15 & 16 & 15 & 14 & 14 & 13 & 15 & 14 & 14 & 13. & 13 \\
\hline \multicolumn{14}{|l|}{20 a $39 \%$ de analfabetismo } \\
\hline NǴmeto de fallceida: & 384 & 424 & 349 & 382 & 350 & 383 & 341 & 346. & 401 & 418 & 373 & 365 & 387 \\
\hline Nümero de imujeros & 216,455 & 221,085 & 205,867 & 230.804 & 235,903 & $237,092$. & 241.971 & 246,982 & 252,132 & 257.422 & 262,462 & 267,888 & 273,459 \\
\hline Tasa de mortallidad & 18 & 19 & 15. & 17 & 15 & 16 & 14 & 14 & 16 & 16 & 14 & 14 & 14 \\
\hline \multicolumn{14}{|l|}{$48 \%$ y inás de analfíbctìneve } \\
\hline Neimece de fallecidar & 308 & 281 & 298 & 293 & 312 & 283 & 277 & 253 & 293 & 273 & $2+2$ & 26.3 & 374 \\
\hline Numeern do mujeres & $120,4.46$ & 122.210 & 124.036 & 125846 & 127.761 & 120,430 & 123,481 & $126,6 i c$. & 130.001 & $133.4 h 2$ & $137, y 72$ & 150.097 & 144,77 \\
\hline Tarsa de martslided & 26 & 23. & 24 & 23 & 24 & 23 & 22 & 20 & 23 & 20 & 19 & 19 & 26 \\
\hline \multicolumn{14}{|c|}{ 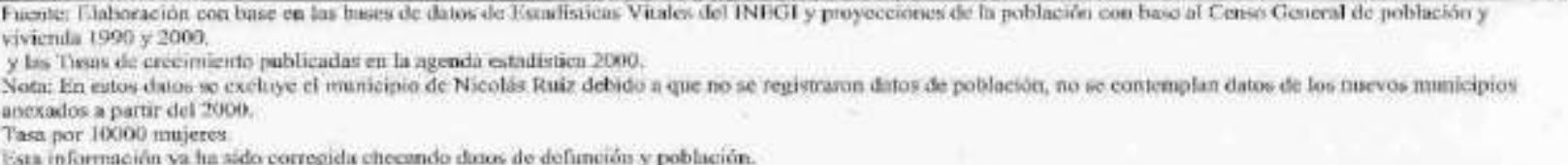 } \\
\hline
\end{tabular}






\section{REFERENCIAS BIBLIOGRÁFICAS}

Anderson K. Coord., 2002, Diccionario de Medicina Océano Mosby. Océano, Barcelona.

Bond Huie, S. A., R. A. Hummer, R. G. Rogers, 2002, «Individual and Contextual Risks of Death among Race and Ethnic Groups in the United States». Journal of Health and Social Behavior, v. 43, n. 3, September, pp. 359-381.

Castoriadis, C., 1983 [1975], La institución imaginaria de la sociedad 2. Tusquets, Barcelona.

Corsi, J. and G. M. Peyrú (coords.), 2003, Violencias sociales. Ariel, Barcelona.

Domenach, J. M., H. Laborit, A. Joxe, J. Galtung, D. Senghaas, O. Klineberg, J. D. Halloran, V. P. Shupilov, K. Poklewski-Koziell, R. Khan, P. Spitz, P. Mertens, E. Boulding, 1981, La violencia y sus causas. UNESCO, París.

Eroza, E., 2006, «Procesos de búsqueda de atención a la salud entre los indígenas tzotziles y tzletales de Los Altos de Chiapas». Tzotziles tzeltales: Seminario Permanente de Antropología Médica, mes de julio, mecanografiado.

Farmer, P., 2004, «Sidney W. Mintz Lecture for 2001. An Anthropology of Structural Violence». Current Anthropology, v. 45, n. 3, pp. 305-322, June.

Freyermuth, G., 2000, «Morir en Chenalhó. Género, generación y etnia, factores constitutivos del riesgos durante la maternidad». Tesis de doctorado. Facultad de Filosofía y Letras, UNAM, México, D. F. 
2003a, Las mujeres de humo. Morir en Chenalhó. Género, etnia y generación, factores constitutivos del riesgo durante la maternidad. CIESAS/Porrúa, México.

2003b, «La Mortalidad Materna y el Subregistro en la Región Indígena de Los Altos de Chiapas. Propuesta de un indicador alterno para su Identificación». Perinatología y Reproducción Humana, v. 17, n. 4, pp. 205-218, septiembre-diciembre, México, D. F.

2007, Mortalidad materna en regiones indígenas: en busca de un indicador alterno. Caso Chiapas. CIESAS/CONACYT, proyecto 103, México.

2008, «Realidad y disimulo: complicidad e indiferencia social en Chiapas frente a la muerte femenina». En Violencia Feminicida en Chiapas. Razones visibles y ocultas de nuestras luchas, resistencias y rebeldías, pp. 129-201, coordinado por Mercedes Olivera. Unicach/Centro de Derechos de la Mujer de Chiapas/Oxfam/Novib, Colección Selva Negra, México.

Freyermuth, G., C. de la Torre, S. Meneses, D. Meléndez, 2009, «Mortalidad materna en Los Altos de Chiapas. Validación de un indicador alterno para identificar subregistro de muerte materna en regiones indígenas». En Estudios Demográficos y Urbanos, v. 24, n. 1, pp. 119-149.

Galtung, Johan, 1981, «Contribución específica de la irenología al estudio de la violencia: tipologías». En La violencia y sus causas, p. 106, Domenach, J. M., H. Laborit, A. Joxe, J. Galtung, D. Senghaas, O. Klineberg, J. D. Halloran, V. P. Shupilov, K. Poklewski-Koziell, R. Khan, P. Spitz, P. Mertens, E. Boulding, UNESCO, París.

Herrera Torres, M. C. et al., 2006, «La economía del grupo doméstico: determinante de muerte materna entre mujeres indígenas de Chiapas». Rev. Panam. Salud Pública, v. 19, n. 2, pp. 69-78, México. 
Hummer, R. A., R. G. Rogers, I. W. Eberstein, 1998, «Sociodemographic Differentials in Adult Mortality: A Review of Analytic Approaches». Population and Development Review, v. 24, n. 3 , pp. 553-578.

Instituto Nacional de Estadística, Geografía e Informática, Inegi, 2006, II Conteo de Población y Vivienda, México.

Jones, C. P., 2000, «Levels of Racism: A Theoretic Framework and a Gardener's Tale». American Journal of Public Health, v. 90, n. 8, pp. 1212-1215, August.

Joxe, Alain, 1981, «Examen crítico de los métodos cuantitativos aplicados a las investigaciones sobre las causas de la violencia», En La violencia y sus causas, pp. 69-89, Domenach, J. M., H. Laborit, A. Joxe, J. Galtung, D. Senghaas, O. Klineberg, J. D. Halloran, V. P. Shupilov, K. Poklewski-Koziell, R. Khan, P. Spitz, P. Mertens, E. Boulding, , UNESCO, París.

Lagarde, M. y S., Lovera, 2005, «Violencia Feminicida en México». Proyecto de Investigación, Comisión especial para conocer y dar seguimiento a las investigaciones relacionadas con los feminicidios en la República Mexicana y a la Procuración de Justicia Vinculada. LIX legislatura Cámara de Diputados. Congreso de la Unión. Marzo, México, D. F.

LIX legislatura Cámara de Diputados. Congreso de la Unión, 2005a, «Por la vida y la libertad de las mujeres». Informe sustantivo de actividades. Comisión especial para conocer y dar seguimiento a las investigaciones relacionadas con los Feminicidios en la República Mexicana y a la Procuración de Justicia Vinculada, México D. F.

LIX legislatura Cámara de Diputados. Congreso de la Unión, 2005b, «Criterios de selección de las entidades de la República Mexicana a investigar». Comisión especial para 
conocer y dar seguimiento a las investigaciones relacionadas con los Feminicidios en la República Mexicana y a la Procuración de Justicia Vinculada, abril, México, D. F.

Lleras-Muney, A., 2005, «The Relationship between Education and Adult Mortality in the United States». The Review of Economic Studies, v. 72, n. 1, pp. 189-221, January.

Meneses, S., 2004, «Semiótica de la otredad. Etnografía de los encuentros interétnicos entre prestadores y usuarios de servicios de salud en Los Altos de Chiapas». Tesis de maestría. CIESAS-Sureste, San Cristóbal de Las Casas, Chiapas, México.

Molla, M. T., J. H. Madans, D. K. Wagener, 2004, «Differentials in Adult Mortality and Activity Limitation by Years of Education in the United States at the End of the 1990s». Population and Development Review, v. 30, n. 4, pp. 625-646, December.

National Research Council, 2000, The consequences of Maternal morbidity and maternal mortality: The report of a workshop. Committee on Population. Editors Holly E. Reed, Marjorie A. Koblinsky and W. Henry Mosley. Comission on Behavioral and Social Sciences and Education. National Academy Press, Washington, D. C.

Nathanson, C. A., 1984, «Sex Differences in Mortality». Annual Review of Sociology, v. 10, pp. 191-213.

Norma Oficial Mexicana NOM-190-SSA1-1999. Prestación de servicios de salud. Criterios para la atención médica de la violencia familiar. México.

Olivera, B. M. (coord.), s.f., «Introducción». En Violencia Feminicida en Chiapas. San Cristóbal de Las Casas, Chiapas, mecanografiado, 273 pp. 
Organización Panamericana de la Salud, OPS, 2003, Clasificación Estadística Internacional de enfermedades y problemas relacionados con la salud, décima revisión, v. 1, p. 1172. Washington, D. C.

The World Bank Group, 2005, World Development Indicators, table 2.19, Mortality. En http://devdata.worldbank.org/ wdi2005/Section2.htm

Programa de Naciones Unidas para el Desarrollo, PNUD, 2004, Informe sobre Desarrollo Humano, México. El reto del desarrollo local. México.

Programa Oportunidades. En http://www.oportunidades.gob.mx/Wn_Quienes_Somos/ index.html [consulta: 21 de abril de 2010].

Secretaría de Salud, SSA, 2002, «Programa de Acción Arranque Parejo en la Vida». México, D. F.

Serrano, E., O. A. Embriz, H. P. Fernández (coords.), 2002, Indicadores Sociodemográficos de los pueblos indígenas de México, pp. 135-136. Instituto Nacional Indigenista/Conapo/UNDP, México.

Sen, A., 2002, «Desigualdad de Género: la misoginia como problema de salud pública». Letras Libres, año IV, n. 40, pp. 12-18, México.

Whitehead, Margaret, 2000, The concepts and principles of equity and health. World Health Organization Regional Office for Europa, Copenhagen, Copenhagen.

Zarco, A., 2009, «Migración, Trabajo sexual Indígena en San Cristóbal de Las Casas, Chiapas: Implicaciones en Salud Sexual y Reproductiva». Tesis de maestría. CIESAS Occidente-Sureste. 


\section{Notas}

${ }^{1}$ Chiapas divide su territorio en 118 unidades político-administrativas agrupadas en 9 regiones. La región de Los Altos se compone de 18 municipios y una población de 585,830 habitantes en 2005, según Instituto Nacional de Estadística y Geografía, Inegi, II Conteo de Población y Vivienda, México, 2006.

${ }^{2}$ El proyecto «Casas de la salud de mujeres indígenas» inició en 2002. Las casas de salud se encuentran en San Quintín, Baja California; Cuetzalan, Puebla; Ometepec, Guerrero; San Mateo del Mar y Matías Romero, Oaxaca; y una más en Chalchihuitán, Chiapas. En 2009 estaban en proceso de apertura tres más: Zongolica, Veracruz; Sihó, municipio de Halachó, Yucatán; y en Pátzcuaro, Michoacán. El objetivo principal del proyecto «Casas de la salud de mujeres indígenas» es «Desarrollar un modelo de atención a la salud y a la violencia familiar e institucional, culturalmente apropiado y que incorpore las prácticas institucionales y tradicionales en beneficio de la población indígena en general y de las mujeres indígenas en particular». Se incluyen actividades de sensibilización sobre la posibilidad de disfrutar de una vida libre de violencia y atención a la salud reproductiva de calidad y culturalmente apropiada; promoción de servicios de salud no discriminatorios, accesibles y de calidad; impulsar la coordinación interinstitucional que incorpore el enfoque de género y etnia; así como garantizar la capacitación y la sensibilización de las parteras, promotoras y mujeres que se involucren con el programa.

3 Título del proyecto «Mortalidad Materna en Regiones Indígenas: Una propuesta metodológica para identificar a municipios de alto riesgo en salud materna (Clave 110, Convocatoria 2003)». Entre los resultados de este proyecto destaca la presencia de un subregistro importante, que es diferencial si tomamos como fuente a Inegi o a las actas de defunción (de 63 y 70\%, respectivamente; Freyermuth et al. 2009).

${ }^{4}$ Se excluyeron Aldama y Santiago El Pinar, de más reciente creación.

${ }^{5}$ La estrategia metodológica fue diseñada conjuntamente con la Dra. Rosario Cárdenas; cfr. Fuentes estadísticas alternas para identificar la mortalidad materna y la utilización de la autopsia verbal, Informe Final: Mortalidad Materna en Regiones Indígenas: Una propuesta Metodológica para identificar a Municipios de Alto Riesgo en Salud Materna, 2007.

${ }^{6}$ Así como la paz no es solamente la ausencia de conflictos armados sino que entraña al progreso, la justicia y el respeto mutuo entre los pueblos (Joxe 1981: 9, cita la resolución 18 C/11.1 de Unesco sobre la paz), la «violencia estructural» no solo entraña la violencia física, sino también la violación sistemática y reiterada de los derechos humanos, como se explicará más adelante.

${ }^{7}$ Parafraseando a Whitehead (2000: 5), el término inequidad tiene una dimensión ética que se refiere a las diferencias, en este caso concreto a la mortalidad de mujeres por causas evitables y/o atendibles. Por ello, estas diferencias pueden ser consideradas injustas e incorrectas. Tal inequidad está basada en la desigualdad de oportunidad de las mujeres para acceder a satisfactores básicos como servicios médicos de calidad y culturalmente competentes; a condiciones de vida dignas por padecer restricciones económicas y sociales; a exposición a riesgos para la salud por condiciones y modos de vida particulares como violencia, estrés, condiciones de trabajo inadecuadas, etcétera; o a la inaccesibilidad a la atención médica atribuible a la discriminación genérica y/o étnica.

${ }^{8}$ Adaptamos el marco conceptual utilizado por Camara Phillys Jones (2000) en su análisis sobre racismo. Por otra parte, Galtung (1969) clasifica la violencia en directa e indirecta, a esta última la llama estructural. No obstante, en su conceptualización señala que no es posible identificar al perpetrador de la violencia; consideramos que la «violencia estructural» se genera a partir de estructuras políticas, económicas y religiosas que son creadas y operadas por personas, lo cual posibilita el reconocimiento de quien la produce. Joxe (1981: 75) aporta que el concepto de violencia estructural que se dio a conocer en 1969 se apoyó, en parte, en el concepto de «violencia institucional» que apareció en el documento de la conferencia de los obispos latinoamericanos de Medellín (1969), el cual, a su juicio, era más político, puesto que declaraba: «no es sencillamente la violencia directa la que mata a la gente, sino también el orden social», por lo que plantea con bastante claridad «la cuestión de la violencia de clase ejercida por el Estado y de la hegemonía — en el sentido gramsciano- sobre la sociedad civil. Se trata siempre de una violencia que se ejerce sobre las personas». Para Galtung (1981: 98-99) la primera categoría de la violencia estructural es la pobreza estructuralmente condicionada, la segunda es la represión estructuralmente condicionada o «intolerancia represiva», la tercera 
es la alienación estructuralmente condicionada o «tolerancia represiva»; por tanto, destaca a la pobreza, la represión y la alienación como elementos fundamentales de su definición de violencia estructural, que a su vez comparten los mismos mecanismos: explotación - división vertical del trabajo-, penetración, fragmentación y marginación. Este autor hace cuatro proposiciones o teoremas, el cuarto declara: «La violencia estructural conduce a la violencia estructural. La pobreza puede conducir a la represión y la represión a la alienación. A veces a través de intermedios de violencia directa vertical» (1981: 101).

${ }^{9}$ Para Farmer (2004: 307) la violencia estructural es ejecutada sistemáticamente — esto es, indirectamentepor todos los que pertenecen a cierto orden social.

${ }^{10}$ Los «marcos de referencia» moldeados por las instituciones a los que nos referimos son parte, de acuerdo con Castoriadis (1983), en la institución imaginaria de la sociedad, del «imaginario social» y sus significaciones; en palabras del autor: «Recíprocamente, las significaciones imaginarias sociales están en y por las "cosas" - objetos e individuos - que los presentifiquen y los figuren, directa o indirectamente, inmediata o mediatamente. Sólo pueden tener existencia mediante su "encarnación", su "inscripción", su presentación y figuración en y por una red de individuos y objetos que ellas "informan"... Pues es lo mismo decir que la sociedad instituye en cada momento un mundo como su mundo o su mundo como el mundo, y decir que instituye un mundo de significaciones, que se instituye al instituir el mundo de significaciones que es el suyo y que sólo en correlación con él existe y puede existir para ella un mundo ... La sociedad da existencia a un mundo de significaciones y ella misma es tan sólo en referencia a ese mundo. [Las significaciones] Son aquello por medio de lo cual y a partir de los cuales los individuos son formados como individuos sociales con capacidad para participar en el hacer y en el representar/decir social, que pueden representar, actuar y pensar de manera compatible, coherente, convergente incluso cuando sea conflictual -el conflicto más violento que pueda desgarrar una sociedad presupone aún una cantidad indefinida de cosas "comunes" o "participables"- las significaciones imaginarias sociales son "inmanentes" a la sociedad que en cada oportunidad se tome en consideración» (Castoriadis 1983: 307, 312, 322, 325). En otras palabras, las significaciones del imaginario social son estructurantes y a su vez estructuradas por una sociedad según su momento histórico.

${ }^{11}$ En http://www.coneval.gob.mx/coneval2/htmls/medicion_pobreza/HomeMedicionPobreza.jsp?categorias =MED_POBREZA,MED_POBREZA-med_multi

${ }^{12}$ Cuadro 2. Defunciones registradas en la población de 15 a 49 años en el estado de Chiapas, periodo 19982002, y Cuadro 3. Defunciones registradas en la población de 15 a 49 años, región Altos de Chiapas, periodo 1998-2002. Freyermuth (2008: 189-190).

13 «...incluyen aquellos decesos relacionados con acontecimientos ambientales y circunstancias como los traumatismos, envenenamientos y homicidios» (OPS 2003: 957).

${ }^{14}$ Se han realizado numerosos estudios desde los años ochenta del siglo XX, sobre la mortalidad diferenciada por sexos y su relación con aspectos sociodemográficos, étnicos, socioeconómicos, de género, en disciplinas como epidemiología, sociología y antropología médica (Nathanson 1984, Hummer et al. 1998, Bond Huie S. et al. 2002, Molla et al. 2004, Lleras-Muney 2005, Freyermuth 2003a).

${ }^{15}$ Salpingoclasia: método anticonceptivo definitivo que consiste en la obstrucción de ambas trompas uterinas mediante mecanismos quirúrgicos. En http://www.imss.gob.mx/salud/Mujer/anticonceptivos/oclusion.htm

${ }^{16}$ El Programa Oportunidades, antes llamado Programa de Educación, Salud y Alimentación, Progresa, es un programa federal para el desarrollo humano de la población en pobreza extrema. Para lograrlo, brinda apoyos en educación, salud, nutrición e ingreso. Es un programa interinstitucional en el que participan la Secretaría de Educación Pública, la Secretaría de Salud, el Instituto Mexicano del Seguro Social, la Secretaría de Desarrollo Social, y los gobiernos estatales y municipales. Incorpora familias haciendo titular a la madre, con lo que se pretende empoderar a las mujeres a través de acciones afirmativas. Adicionalmente, tres de cuatro de sus estrategias se enfocan a la atención materna: Paquete básico de salud, Autocuidado de la salud a través de la educación para la salud, y Reforzamiento de la oferta de los servicios de salud. Una de las estrategias es la corresponsabilidad, que consiste en que las familias beneficiarias deben registrarse en la clínica de salud más cercana y cumplir con citas periódicas y asistir a las charlas de educación para la salud. En http://www.oportunidades.gob.mx/Wn_Quienes_Somos/index.html)

${ }^{17}$ Véase, Zarco 2009. 
${ }^{18}$ El Programa de Acción: «Arranque Parejo en la Vida», tiene como objetivo general «lograr una cobertura universal y condiciones igualitarias de atención con calidad a las mujeres durante el embarazo, el parto y el puerperio, así como a las niñas y niños desde antes de su nacimiento hasta los dos años de edad» (SSA 2002: 13).

${ }^{19}$ También conocida como Anemia aplásica: Deficiencia de todos los elementos formes de la sangre debido a un fracaso de la capacidad regeneradora de la médula ósea. Puede responder a una enfermedad neoplásica de la médula o, con mayor frecuencia, a su destrucción por exposición a agentes químicos tóxicos, radiaciones ionizanes o algunos fármacos, antibióticos y otros. Existe también una forma idiopática [de origen desconocido] rara de la enfermedad (Diccionario de Medicina Océano Mosby).

${ }^{20}$ Se ha estudiado el efecto de la muerte materna en el grupo doméstico (National Research Council 2000, Freyermuth 2003a, Herrera et al. 2006) a esfera mundial, como en México, observando lo siguiente: «Cuando una mujer muere o se enferma, o tiene una complicación durante o antes del parto, las consecuencias tienen un efecto potencial no solamente en la mujer misma, sino en su familia y en la comunidad de diferentes maneras. La morbilidad y la mortalidad pueden tener costos psicológicos y físicos en las mujeres, niños y otros miembros de la familia. Además, la educación de los niños y su cuidado pueden verse afectados por la enfermedad o muerte de su madre. También hay costos potenciales en la familia o en la economía familiar asociadas con la enfermedad y la muerte, tales como cambios en la distribución del trabajo, productividad, consumo, inversión y costos directos ya sean médicos o en el funeral. Finalmente, la comunidad así como normas sociales y su comportamiento, pueden verse afectados tanto por la enfermedad como por el fallecimiento, especialmente si la mujer enferma o fallecida es o era un miembro importante en su comunidad. Por lo que respecta a cualquier enfermedad o fallecimiento en adultos, la respuesta por parte del grupo doméstico, la comunidad y la sociedad determina si una familia, comunidad o sociedad puede lidiar con las consecuencias de la morbi-mortalidad materna. Las consecuencias pueden variar substancialmente dependiendo de los roles del miembro de la familia enfermo o muerto» (National Research Council 2000: 4-5; traducción de las autoras). En Chiapas, G. Freyermuth (2003a) ha documentado particularmente la desestructuración familiar posterior a una muerte materna en el grupo doméstico afectado; abuso sexual por parte del padre hacia las hijas; matrimonios precoces de las hijas, utilizados para salir de su grupo doméstico ante la llegada de una nueva pareja del padre; migración cuando se conforman nuevas parejas. Además, recientemente se ha documentado en Chiapas el efecto de las muertes maternas en el grupo familiar/doméstico a lo largo del tiempo (Herrera et al. 2006: 74): A los seis meses se ven efectos como ruptura del esquema familiar, menor atención a los hijos; mayor probabilidad de muerte en hijos menores de un año; deserción escolar; desnutrición y la aparición de enfermedades en el grupo familiar. Desde un año de la muerte se observan cambios en las responsabilidades y en las actividades domésticas —asumidas por las hijas adolescentes o preadolescentes -; crisis en la economía doméstica; pérdida de la cosecha; suspensión de la beca del Programa Oportunidades. Después de cinco años de la muerte el grupo doméstico aún paga deudas por gastos funerarios, por la compra de alimentos tras la pérdida de la cosecha; el cónyuge tiene una nueva pareja; los hijos se sujetan a las decisiones de la nueva pareja; cambio de rol en el núcleo familiar; o muerte del cónyuge por alcoholismo. En el ámbito comunitario se puede observar en el periodo de los primeros seis meses que los hijos se van a vivir con los abuelos, pobreza del clan; al año puede ocurrir migración de los hijos y deserción escolar; a los cinco años presión por fuentes de trabajo; redistribución de la tierraherencia-, cambios de esquema comunitario y migración.

${ }^{21}$ No obstante, la causalidad de la enfermedad de Marcela puede relacionarse con la exposición a agroquímicos durante su trabajo en el cafetal.

${ }^{22}$ Los actos de comisión por parte de servidores públicos van desde la modificación de las causas de muerte en las actas de defunción, subregistro de fallecimientos - p. ej. muerte materna-, incumplimiento de horarios de trabajo — en centros de salud, escuelas—, no atención — cierre de puertas de acceso a los usuarios para aparentar que no hay nadie-, etcétera.

Fecha de recepción: 11 de febrero de 2010.

Fecha de aceptación: 27 de abril de 2010. 